\title{
Speech Therapy in Primary Progressive Aphasia: A Pilot Study
}

\author{
Luísa Farrajota ${ }^{\mathrm{a}, \mathrm{b}}$ Carolina Maruta $^{\mathrm{b}, \mathrm{c}}$ João Maroco ${ }^{\mathrm{d}}$ \\ Isabel Pavão Martins ${ }^{b} \quad$ Manuela Guerreiro $^{a-c}$ \\ Alexandre de Mendonça ${ }^{a, c}$

\begin{abstract}
${ }^{a}$ Memory Clinic, ${ }^{b}$ Laboratory of Language Research, Faculty of Medicine of Lisbon and Institute of Molecular Medicine and Faculty of Medicine of Lisbon, and dISPA-IU,
\end{abstract} \\ Hospital de Santa Maria, 'Laboratory of Neurosciences and Department of Neurology, \\ Lisbon, Portugal
}

\section{Key Words}

Primary progressive aphasia - Dementia - Cognitive rehabilitation - Speech and language therapy

\begin{abstract}
Background: Primary progressive aphasia (PPA) is a neurodegenerative disorder with no effective pharmacological treatment. Cognition-based interventions are adequate alternatives, but their benefit has not been thoroughly explored. Our aim was to study the effect of speech and language therapy (SLT) on naming ability in PPA. Methods: An open parallel prospective longitudinal study involving two centers was designed to compare patients with PPA submitted to SLT (1 h/week for 11 months) with patients receiving no therapy. Twenty patients were enrolled and undertook baseline language and neuropsychological assessments; among them, 10 received SLT and 10 constituted an age- and education-matched historical control group. The primary outcome measure was the change in group mean performance on the Snodgrass and Vanderwart naming test between baseline and follow-up assessments. Results: Intervention and control groups did not significantly differ on demographic and clinical variables at baseline. A mixed repeated measures ANOVA revealed a significant main effect of therapy $(F(1,18)=$ $10.763 ; p=0.005)$ on the performance on the Snodgrass and Vanderwart naming test. Conclusion: Although limited by a non-randomized open study design with a historical control group, the present study suggests that SLT may have a benefit in PPA, and it should prompt a randomized, controlled, rater-blind clinical trial.




\section{Introduction}

Progressive cognitive syndromes with circumscribed deficits in the language domain and preserved intellect, associated with atrophy of the left-dominant hemisphere, have been recognized for more than a century [1]. However, interest in these clinical conditions only flourished in the 1980s following Mesulam's [2] publication of a series of 6 patients who in late middle age developed a 'slowly progressive aphasia', subsequently renamed 'primary progressive aphasia' (PPA) [3].

PPA is a clinical syndrome with an insidious onset, characterized by a progressive and isolated deterioration of word finding, object naming, fluency, syntax, and word comprehension, during at least a 2-year period and without an identifiable cause other than atrophy (ruling out non-neurodegenerative etiologies, such as stroke or malignancy). Memory, visuospatial skills, executive and social abilities should remain relatively preserved during the first years of the disease and, as other areas of cognition become eventually impaired, language still remains the domain that deteriorates faster [4].

Word-finding difficulties and anomia are amongst the earliest symptoms of PPA, though they evolve to different linguistic profiles [5]. Attempts to use the traditional taxonomy of aphasias (Broca's and Wernicke's aphasia) have not been entirely successful, possibly because degeneration tends to induce more widespread, less severe, and slowly evolving patterns of brain dysfunction. The non-fluent form of PPA has been referred to as progressive non-fluent aphasia [6], whereas the fluent form is known as semantic dementia [7, 8] due to the presence of a progressive disorder of the semantic memory [9]. Cases of PPA can be classified into variants based on linguistic/neuropsychological features [10-13], each variant being associated with distinct patterns of atrophy [12] and different likelihoods of underlying pathologies [14-16]. Recently, a new classification of PPA into subtypes has reached consensus, and three variants are now formally recognized (agrammatic, semantic, and logopenic) [17].

PPA is a very disabling disorder for which there is, at present, no available treatment. A few pharmacological trials (using bromocriptine, galantamine, and memantine) conducted so far have enrolled small numbers of patients and produced inconclusive results [18-21], and there have been no trials with other therapies. Taking into account this discouraging perspective, the implementation of non-pharmacological procedures, specifically designed to compensate for progressive language deficits, may seem a feasible alternative.

There is evidence from other neurodegenerative conditions that cognition-based interventions may be effective in maintaining or improving cognitive function and perhaps delay progression to dementia. A Cochrane collaboration study recently reviewed 36 trials on the effect of cognitive stimulation on mild cognitive impairment, revealing some beneficial effect of this type of intervention on measures of immediate and delayed recall, when comparing groups subjected to intervention and groups with no stimulation [22]. Similar results have also been reported in patients with mild dementia [23].

Speech and language therapy (SLT) has been extensively used in patients with aphasia of different etiologies and has been shown to be effective [24-28]. It aims to maximize the subject's communicative abilities. A recent meta-analysis [29] identified 30 controlled trials with speech therapy, performed between 1969 and 2009, showing beneficial effects in a variety of language measures (spontaneous speech, gestural use, aphasia severity, expressive written language, and comprehension). Functional neuroimaging studies have confirmed these results by showing neural reorganization following SLT [30, 31].

Because PPA affects mostly language, it is reasonable to presume that SLT might be effective in this condition given the fact that other behavioral interventions have proved to be useful in degenerative diseases. To date, case reports and single-subject experimental research have been presented [32-34]; however, the scarce number of participants and the ab- 
sence of a control intervention in the majority of the studies limit the significance of the results. Attempts to introduce other approaches based on training with a text-to-speech alternative communication device or sign language were also reported [35], but again the generalization of these preliminary encouraging results appears difficult.

The aim of our study was to find out whether a SLT program can mitigate language decline in PPA, by comparing a group exposed to this intervention with a historical control group of PPA patients who did not undergo any stimulation. Specifically, we tested the hypothesis that patients subjected to speech therapy would show significantly less decline over time on expressive language measures, namely naming ability, as compared to the control group. If positive results were found, they would encourage carrying out a formal randomized controlled trial to establish the efficacy of SLT in PPA. This intervention would hopefully assist in the maintenance or even transitory amelioration of patients' linguistic skills, promoting their ability to communicate and their quality of life.

\section{Materials and Methods}

\section{Participants}

Participants were patients referred to language/neuropsychological assessments at the two participating clinical institutions in Lisbon and who fulfilled the diagnostic criteria for PPA [17]. The intervention group comprised 10 patients who underwent speech therapy sessions at the institution (Memory Clinic) that offered the patients the possibility of being enrolled in a SLT program. The controls were 10 age- $( \pm 2$ years $)$ and education- $( \pm 3$ years $)$ matched PPA patients consecutively selected from the clinical institutions databases (Memory Clinic and Laboratory of Language Research) if they had at least two language/neuropsychological assessments and were not subjected to SLT. The study was approved by the local ethics committee.

\section{Inclusion Criteria}

All patients fulfilled the following criteria:

- The presence of PPA, according to the criteria recently proposed by Gorno-Tempini et al. [17]:

- Insidious onset and gradual progressive impairment of language production, object naming, syntax, or word comprehension, apparent during conversation or through speech and language assessments;

- Activities of daily living are maintained except those related to language (e.g. using the telephone);

- Prominent, isolated language deficit at symptom onset, during the initial phase of the disease and at time of examination;

- Absence of prominent episodic and nonverbal memory loss and visuospatial impairment during the initial stages of the illness;

- Other cognitive functions may be affected later on, but language remains the most impaired domain throughout the course of the illness;

- Absence of prominent behavioral disturbances at the time of diagnosis;

- The pattern of deficits is not better accounted for by other non-degenerative diseases of the nervous system (e.g. stroke or tumor), as ascertained by neuroimaging, or medical disorders;

- Cognitive disturbance is not better accounted for by a psychiatric diagnosis;

- Right-handedness;

- Native Portuguese speakers;

- Complete language/neuropsychological assessments. 


\section{Exclusion Criteria}

- Presence of dementia, according to DSM-IV-TR criteria [36];

- Other neurological or psychiatric disorders that might induce language or other cognitive deficits (e.g. stroke, brain tumor, traumatic brain injury, epilepsy, severe and uncontrolled medical illness, namely, hypertension, metabolic, endocrine, toxic or infectious disease).

\section{Procedures}

In all cases, clinical history was evaluated, and they underwent neurological examination and a detailed cognitive assessment which comprised language and neuropsychological evaluations.

An experienced neuropsychologist (M.G.) performed the neuropsychological assessment. The test battery consisted of the nonverbal subtests of the Battery of Lisbon for the Assessment of Dementia (BLAD [37]). Since results in many neuropsychological tests are somewhat difficult to interpret in patients with PPA, due to test reliance on verbal directions, verbal stimuli, and/or verbal responses, nonverbal tests were preferred to evaluate different cognitive domains (sustained attention, motor and graphomotor initiative, visuoconstructive abilities, visual memory, and matrix reasoning). Activities of daily living and behavioral changes were also assessed during the interview with the caregivers.

\section{Language Assessment}

At the baseline evaluation, patients were assessed by a speech therapist (L.F.) using a comprehensive language test battery (Lisbon Aphasia Examination Battery, BAAL [38-40]) that included the following instruments: (a) picture description (Goodglass and Kaplan's cookie theft [41]) for analysis of spontaneous speech; (b) visual object naming (BAAL); (c) Snodgrass and Vanderwart naming test [42]; (d) a short 22-item version of the token test [43]; (e) object identification and comprehension of oral commands (BAAL); (f) word and sentence repetition (BAAL); (g) text reading and comprehension (BAAL); (h) writing sentences to dictation (BAAL), and (h) spontaneous writing of a text. A global language measure, the Aphasia Quotient (AQ), was calculated for all patients by adding the scores (as percentages) of 4 BAAL subtests (fluency, object naming, repetition, and comprehension of oral commands) and dividing the sum by 4 [44]. Classification into PPA subtypes (agrammatic, semantic, and logopenic) followed specific criteria outlined by Gorno-Tempini et al. [17].

\section{Speech Therapy Intervention}

SLT comprised 60-min weekly sessions conducted by a trained speech therapist with experience in PPA (L.F.). The main goal of this intervention was the improvement of the patient's ability to communicate by verbal means with others in everyday life through a stimulation approach [45]. This method is considered an individualized multimodality stimulation approach [46]. Improvement in comprehension and expression of both spoken and written language was targeted through different exercises such as picture naming, description of picture actions, complex auditory-verbal comprehension, reading and writing, facilitation of expression of feelings and opinions, and enhancement of conversational skills. The patient's attention is directed to the content he/she wants to express [47]. These exercises were completed during sessions with the speech therapist. Depending on the patient's education level, motivation, and aphasia severity, about 5-10 of these exercises were given as homework. Conversational success, with the focus on functional outcome [48, 49], was also explored and stimulated by the use of all sorts of communication strategies (speaking, writing, drawing or gesturing). Thus, authentic opportunities are provided to patients to 
develop effective strategies for overcoming potential obstacles to communication. The main goal was always the exchange of ideas in a naturalistic and interactive manner in a supported conversation [50]. The main conversational topics usually included everyday life stories, recent news, episodes of soap operas and sports, restaurants, shops, family/friends, social life, and emotions. This was accomplished through picture description about personal safety, nonsense/unreal and decision-making situations. Tasks also included description and organization of sequences.

\section{Primary Outcome Measure}

The primary outcome measure was the mean change in the Snodgrass and Vanderwart naming test scores before and after the intervention. This test assesses the ability to visually name 128 black and white picture drawings [42]. Picture naming has been reported as the measure most positively affected by speech therapy in stroke aphasic patients [51,52], and impairment of word finding (leading to anomia during visual confrontation naming) is the single most prominent deficit in PPA [4].

The remaining language measures (token test, object naming, word repetition, comprehension of oral commands, and object identification) were considered as secondary outcome measures.

\section{Statistical Analysis}

Statistical analysis was performed using IBM SPSS Statistics (version 19.0, SPSS, Chicago, Ill., USA). A significance level of 0.05 was used in the analyses. Since the variables displayed normal distribution and homogeneity of variances ( $p>0.05)$, demographic and clinical numerical variables were compared in both groups using the parametric independent samples Student's $t$ test. The Pearson $\chi^{2}$ test was used for categorical variables. A mixed repeated measures analysis of variance (ANOVA) was performed to evaluate the effect of speech therapy on primary as well as secondary outcome measures, using the initial and the follow-up evaluations as the within-subjects condition, and the presence or absence of intervention as the between-subjects condition. Since both the severity of aphasic changes at baseline and the time elapsed could decisively influence the outcome, the initial AQ and the evolution time between baseline and follow-up were entered as covariates in the analysis.

\section{Results}

Table 1 shows the demographic and clinical data of both the intervention and the control group. Overall, more men participated in the study (70\%). There were no statistically significant differences in the demographic and clinical data of the two groups. The SLT group and the control group did not significantly differ concerning aphasia severity as assessed by the AQ ( $p=0.720$; table 1). No significant differences were found in the mean scores of the Snodgrass and Vanderwart naming test at the baseline assessment between patients who underwent SLT (110.8 \pm 18.2) and controls (87.7 $\pm 23.2 ; \mathrm{t}(18)=1.402 ; \mathrm{p}=0.178)$.

\section{Effect of Speech Therapy}

The intervention group received on average 37.1 speech therapy sessions during 11.1 months (table 1).

As shown in table 2, a mixed repeated measures ANOVA was conducted to assess whether there were statistical differences in the primary outcome measure with regard to evolution (baseline vs. follow-up) and therapy (with vs. without speech therapy). After controlling for evolution times and the initial AQ, a significant main effect of therapy $(p=0.005)$ was found 

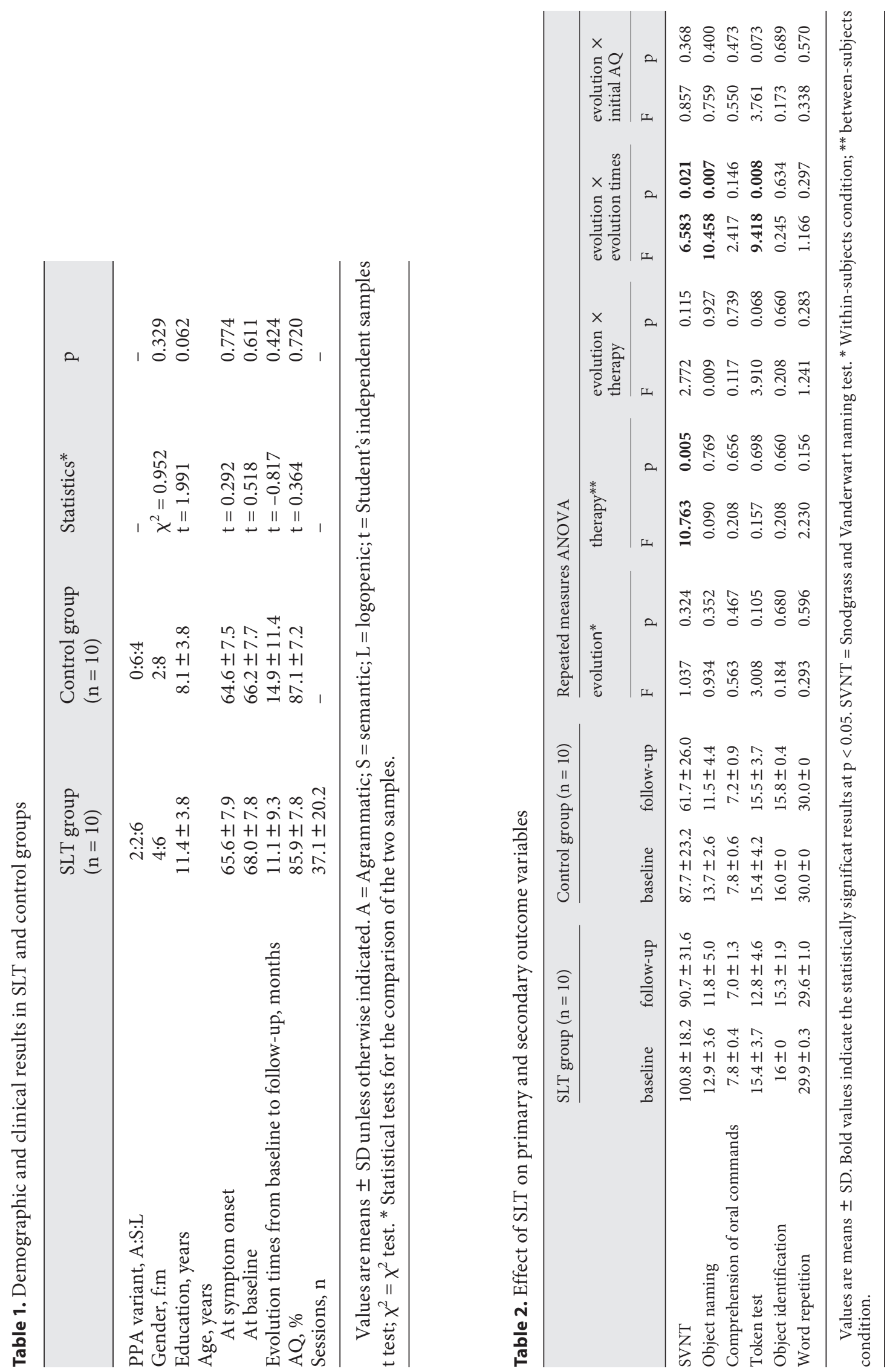
on the primary variable, the performance on the Snodgrass and Vanderwart naming test (table 2), meaning that patients subjected to SLT declined less than controls. The interaction between evolution and therapy was not significant $(\mathrm{p}=0.083)$; however, significant interactions were found between evolution and evolution times for the primary $(\mathrm{p}=0.021)$ and secondary outcome measures (token test, $\mathrm{p}=0.008$; table 2 ), reflecting a more pronounced decline for longer follow-ups.

\section{Discussion}

The present study suggests that there is a tendency for a less severe decline of language, namely concerning naming abilities, in PPA patients subjected to SLT when compared with a control group that did not undergo SLT. We found that patients subjected to SLT declined significantly less in the primary variable, the Snodgrass and Vanderwart naming test.

An effect of language rehabilitation on picture naming has been previously reported, but only based on case reports and single-subject experimental research. Louis et al. [32] addressed the impact of intensive training on phonological skills in 3 PPA patients over a 42 day training period. The authors found that, in spite of global worsening of language abilities over intervention, some language functions (fluency, written comprehension, repetition, reading, and reduction of phonemic paraphasias) either remained stable or improved. Another study [33] followed 2 individuals with progressive language impairment and a stroke aphasia patient in a daily 90 -min semantically based intensive treatment to improve lexical retrieval, during 16 days. Results indicated that all patients showed improved lexical retrieval on a generative naming task for specific categories trained during intervention. However, only 1 of the PPA patients and the stroke aphasia patient maintained improved performance on follow-up at 3 weeks and 4 months after treatment. The same research group reported similar results with the therapy of a logopenic PPA patient who performed follow-up assessment at 3 weeks, 4 and 6 months after intervention. This patient also presented an improvement in naming on the training task, which generalized towards an improvement in standardized measures of confrontation naming [34].

It must be emphasized that it would be particularly important to find effective nonpharmacological approaches to treat PPA, since no pharmacological treatments are currently available. A few clinical trials testing different drugs can be found in the literature, but they reported inconsistent results. The study of the effect of bromocriptine on the performance of various language tasks revealed that it did not produce significant effects on language measures during a 15-week double-blind cross-over study, when comparing PPA and placebo groups [18]. Another open-label study, this time with galantamine, in a sample of 36 behavioral frontotemporal dementia and PPA patients showed a non-significant trend for efficacy in the aphasic subgroup, suggesting that aphasia scores were more stable in the treatment than in the placebo group [19]. A similar open-label study with memantine [20] reported a relative stability on the ADAS-Cog over the 52 weeks of the study in progressive nonfluent aphasia patients, whereas patients with semantic dementia declined. Finally, a more recent double-blind, placebo-controlled trial showed a slight positive effect of this same drug, consisting of a smaller decline on the Western Aphasia Battery (WAB) aphasia quotient in the groups administered the drug than in the placebo group [21].

Considering cognitive therapy for neurodegenerative disorders in a broader context, it has certainly been difficult to find unequivocal benefits of this sort of interventions, for example, in mild cognitive impairment and mild dementia [22, 23]. However, the study of a specific form of cognitive intervention (speech therapy) in a homogenous group presenting a limited cognitive dysfunction (language impairment) may be particularly advantageous to 
reveal beneficial effects on cognitive performance. If we consider that the majority of techniques used in cognitive rehabilitation are designed to stimulate a broader range of impaired and/or preserved cognitive functions, the use of SLT in PPA patients can be representative of the possible impact of rehabilitation in neurodegenerative diseases.

As strengths of our study we underline the use of a sample followed longitudinally, the inclusion of a matched control group, and the fact that language intervention was always conducted by the same speech therapist, allowing the use of a consistent treatment structure (though adapted to each case).

We also acknowledge several limitations of the present work in the context of a pilot study undertaken to prompt future prospective trials. First of all, allocation to the treatment or the control group was not randomized, even though patients in both groups were age- and education-matched. This constitutes an important limitation, since the groups might differ in other variables relevant for the primary outcome measure that were not controlled for. However, we feel there was no clear allocation bias in the sense that patients more likely to benefit would have be directed to SLT. In fact, patients were offered the possibility of entering a SLT program at one institution, and this program was not available at the other institution. Thus, the allocation was essentially dependent on the clinical center and not on patients' characteristics, although it can be argued that socioeconomical status might have driven the choice of the center. Another limitation of the present study was a considerable variability of follow-up times in the intervention and control groups. This is partially due to the retrospective nature of the analysis that did not adhere to a formal assessment protocol at predetermined follow-up intervals, and to the historical nature of the control sample. A final limitation is that, due to the lack of a control intervention, the benefit of the language therapy might, at least partially, reflect nonspecific effects of contact with the speech therapist.

Future interesting directions in this area might be to consider the use of functional magnetic resonance imaging to observe possible changes in brain activation patterns over time as a result of speech therapy, as previously reported in stroke patients [31, 53]. On the other hand, a particular intervention might not equally impact on each syndrome, so that future prospective trials should take into account the specific PPA subtypes. Finally, future studies should not be confined to specific language measures, but address the possible impact of speech therapy on broader functional communication abilities, which are extensively stimulated during training sessions and might have important functional benefits. Language deficits can be extremely disabling as they disrupt the ability to express even basic thoughts and needs. The majority of aphasic patients are unable to maintain their previous job and suffer from a reduction of their social contacts, causing great problems at individual, social, and socio-economic levels [54]. In the therapy context, the patient learns new strategies to use in everyday life that improve his/her capacity to communicate with others and interact with the environment, allowing engagement in many language-based activities (e.g. making appointments, schedules, and using the telephone). As a consequence, the linguistic processes which are failing are further stimulated [55]. In fact, some studies suggest that therapy can have an impact on patients' views of their communicative activities and life participation by increasing their activity ratings, especially those that require active communication [52]. The use of functional communication scales such as the ASHA Functional Assessment of Communication Skills for Adults (ASHA FACS [56]) in future trials would provide more ecologically valid measures for everyday communication.

In conclusion, the present study suggests that the implementation of a non-pharmacological, language-based intervention in PPA might attenuate the progression of some language deficits, and should prompt further studies using randomized, controlled, rater-blind procedures to ascertain the effective role of speech therapy in PPA. 


\section{Acknowledgments}

The authors would like to thank Jason Warren (Dementia Research Centre, Institute of Neurology, University College of London, UK) for the thorough revision of the manuscript, and also acknowledge the facilities provided by Memoclínica. C.M., M.G., and A.d.M. receive funding from Fundação para a Ciência e Tecnologia.

\section{References}

1 Pick A: Über die Beziehungen der senilen Hirnatrophie zur Aphasie. Prager Med Wochenschr 1892; 17:165-167.

-2 Mesulam MM: Slowly progressive aphasia without generalized dementia. Ann Neurol 1982;11:592598.

-3 Mesulam MM: Primary progressive aphasia - differentiation from Alzheimer's disease. Ann Neurol 1987;22:533-534.

4 Mesulam MM: Primary progressive aphasia. Ann Neurol 2001;49:425-432.

-5 Mesulam MM, Wieneke C, Thompson C, Rogalsky E, Weintraub S: Quantitative classification of primary progressive aphasia at early and mild impairment stages. Brain 2012;135:1537-1553.

-6 Grossman M, Mickanin J, Onishi K, Hughes E, D’Esposito M, Ding XS: Progressive nonfluent aphasia: language, cognitive and PET measures contrasted with probable Alzheimer's disease. J Cogn Neurosci 1996;8:135-154.

7 Snowden JS, Goulding PJ, Neary D: Semantic dementia: a form of circumscribed cerebral atrophy. Behav Neurol 1989;2:167-182.

8 Hodges JR, Patterson K, Oxbury S, Funnell E: Semantic dementia. Progressive fluent aphasia with temporal lobe atrophy. Brain 1992;115:1783-1806.

-9 Warrington EK: The selective impairment of semantic memory. Q J Exp Psychol 1975;27:635-657.

-10 Hodges JR, Patterson K: Nonfluent progressive aphasia and semantic dementia: a comparative neuropsychological study. J Int Neuropsychol Soc 1996;2:511-524.

-11 Neary D, Snowden JS, Gustafson L, Passant U, Stuss D, Black S, Freedman M, Kertesz A, Robert PH, Albert M, Boone K, Miller BL, Cummings J, Benson DF: Frontotemporal lobar degeneration: a consensus on clinical diagnostic criteria. Neurology 1998;51:1546-1554.

-12 Gorno-Tempini ML, Dronkers NF, Rankin KP, Ogar JM, Phengrasamy L, Rosen HJ, Johnson JK, Weiner MW, Miller BL: Cognition and anatomy in three variants of primary progressive aphasia. Ann Neurol 2004;55:335-346.

-13 Wilson SM, Ogar JM, Laluz V, Growdon M, Jang J, Glenn S, Miller BL, Weiner MW, Gorno-Tempini ML: Automated MRI-based classification of primary progressive aphasia. Neuroimage 2009;47: 1558-1567.

-14 Josephs KA, Duffy JR, Strand EA, Whitwell JL, Layton KF, Parisi JE, Hauser MF, Witte RJ, Boeve BF, Knopman DS, Dickson DW, Jack CR Jr, Petersen RC: Clinicopathological and imaging correlates of progressive aphasia and apraxia of speech. Brain 2006;129:1385-1398.

-15 Knibb JA, Xuereb JH, Patterson K, Hodges JR: Clinical and pathological characterization of progressive aphasia. Ann Neurol 2006;59:156-165.

-16 Rabinovici GD, Jagust WJ, Furst AJ, Ogar JM, Racine CA, Mormino EC, O’Neil JP, Lal RA, Dronkers NF, Miller BL, Gorno-Tempini ML: Abeta amyloid and glucose metabolism in three variants of primary progressive aphasia. Ann Neurol 2008;64:388-401.

-17 Gorno-Tempini ML, Hillis AE, Weintraub S, Kertesz A, Mendez M, Cappa SF, Ogar JM, Rohrer JD, Boeve BF, Manes F, Dronkers NF, Vandenberghe R, Rascovsky K, Patterson K, Miller BL, Knopman DS, Hodges JR, Mesulam MM, Grossman M: Classification of primary progressive aphasia and its variants. Neurology 2011;76:1006-1014.

-18 Reed DA, Johnson NA, Thompson C, Weintraub S, Mesulam MM: A clinical trial of bromocriptine for treatment of primary progressive aphasia. Ann Neurol 2004;56:750.

19 Kertesz A, Morlog D, Light M, Blair M, Davidson W, Jesso S, Brashear R: Galantamine in frontotemporal dementia and primary progressive aphasia. Dement Geriatr Cogn Disord 2008;25:178-185. 
20 Boxer AL, Lipton AM, Womack K, Merrilees J, Neuhaus J, Pavlic D, Gandhi A, Red D, Martin-Cook K, Svetlik D, Miller BL: An open-label study of memantine treatment in 3 subtypes of frontotemporal lobar degeneration. Alzheimer Dis Assoc Disord 2009;23:211-217.

-21 Johnson NA, Rademaker A, Weintraub S, Gitelman D, Wienecke C, Mesulam M: Pilot trial of memantine in primary progressive aphasia. Alzheimer Dis Assoc Disord 2010;24:308.

22 Martin M, Clare L, Altgassen AM, Cameron MH, Zehnder F: Cognition-based interventions for healthy older people and people with mild cognitive impairment. Cochrane Database Syst Rev 2011; 19:CD006220.

23 Woods B, Aguirre E, Spector AE, Orrell M: Cognitive stimulation to improve cognitive functioning in people with dementia. Cochrane Database Syst Rev 2012;2:CD005562.

24 Robey RR: The efficacy of treatment for aphasic persons: a meta-analysis. Brain Lang 1994;47:582608.

-25 Robey RR: A meta-analysis of clinical outcomes in the treatment of aphasia. J Speech Lang Hear Res 1998;41:172-187.

-26 Mazzoni M, Vista M, Geri E, Avila L, Bianchi F, Moretti P: Comparison of language recovery in rehabilitated and matched non-rehabilitated aphasic patients. Aphasiology 1995;9:553-563.

27 Leal MG, Farrajota L, Fonseca J, Guerreiro M, Castro-Caldas A: The influence of speech therapy on the evolution of stroke aphasia. J Clin Exp Neuropsychol 1993;15:399.

-28 Basso A, Macis M: Therapy efficacy in chronic aphasia. Behav Neurol 2011;24:317-325.

29 Kelly H, Brady MC, Enderby P: Speech and language therapy for aphasia following stroke. Cochrane Database Syst Rev 2010;12:CD000425.

-30 Léger A, Démonet JF, Ruff S, Aithamon B, Touyeras B, Puel M, Boulanouar K, Cardebat D: Neural substrates of spoken language rehabilitation in an aphasic patient: an fMRI study. Neuroimage 2002; 17:174-183.

- 31 Peck KK, Moore AB, Crosson BA, Gaiefsky M, Gopinath KS, White K, Briggs RW: Functional magnetic resonance imaging before and after aphasia therapy: shifts in hemodynamic time to peak during an overt language task. Stroke 2004;35:554-559.

-32 Louis M, Espesser R, Rey V, Daffaure V, Di Cristo A, Habib M: Intensive training of phonological skills in progressive aphasia: a model of brain plasticity in neurodegenerative disease. Brain Cogn 2001;46:197-201.

-33 Henry ML, Beeson PM, Rapcsak SZ: Treatment for lexical retrieval in progressive aphasia. Aphasiology 2008;22:826-838.

-34 Beeson PM, King RM, Bonakdarpour B, Henry ML, Cho H, Rapcsak SZ: Positive effects of language treatment for the logopenic variant of primary progressive aphasia. J Mol Neurosci 2011;45:724-736.

- 35 Pattee C, Von Berg S, Ghezzi P: Effects of alternative communication on the communicative effectiveness of an individual with a progressive language disorder. Int J Rehabil Res 2006;29:151-153.

36 American Psychiatric Association: Diagnostic and Statistical Manual of Mental Disorders (ed 4 Text Review). Lisboa, Climepsi, 2001.

37 Garcia C: A doença de Alzheimer. Problemas de diagnóstico clínico. PhD Thesis presented to the Faculty of Medicine of Lisbon, 1984.

38 Damásio AR: Neurologia da linguagem. PhD Thesis presented to the Faculty of Medicine of Lisbon, 1973.

39 Castro-Caldas A: Diagnóstico e evolução das afasias de causa vascular. PhD Thesis presented to the Faculty of Medicine of Lisbon, 1973.

40 Ferro JM: Neurologia do comportamento. Estudo da correlação com a tomografia axial computorizada. PhD Thesis presented to the Faculty of Medicine of Lisbon, 1986.

41 Goodglass H, Kaplan E: Assessment of Aphasia and Related Disorders. Philadelphia, Lea and Febinger, 1972 .

-42 Snodgrass JG, Vanderwart M: A standardized set of 260 pictures: norms for name agreement, image agreement, familiarity, and visual complexity. J Exp Psychol Hum Learn 1980;6:174-215.

43 De Renzi E, Vignolo LA: The token test: a sensitive test to detect receptive disturbances in aphasics. Brain 1962;85:665-678.

44 Ferro JM, Kertesz A: Is your aphasic like mine? A study of comparative classification. 6th European International Neuropsychological Society Conference, Lisbon, 1983.

-45 Schuell H, Carroll V, Street BS: Clinical treatment of aphasia. J Speech Hear Disord 1955;20:43-53. 
46 Duffy JR, Coelho CA: Schuell's stimulation approach to rehabilitation; in Chapey R (ed): Language Intervention Strategies in Aphasia and Related Neurogenic Communication Disorders (ed 4). Baltimore, Lippincott Williams and Wilkins, 2001, pp 341-382.

-47 Wepman JM: Aphasia: language without thought or thought without language? ASHA 1976;18:131136.

48 Simmons-Mackie N: Social approaches to aphasia intervention; in Chapey R (ed): Language Interventions Strategies in Aphasia and Related Neurogenic Communication Disorders (ed 4). Baltimore, Lippincott Williams and Williams, 2001, pp 246-266.

-49 Holland A, Fridriksson J: Aphasia management during the early phases of recovery following stroke. Am J Speech Lang Pathol 2011;10:19-28.

50 Kagan A: Supported conversation for adults with aphasia: methods and evaluation. PhD Thesis presented to the Institute of Medical Sciences, University of Toronto, Canada, 1999.

-51 Bhogal SK, Teasell R, Speechley M: Intensity of aphasia therapy, impact on recovery. Stroke 2003;34: 987-993.

52 Best W, Grassly J, Greenwood A, Herbert R, Hickin J, Howard D: A controlled study of changes in conversation following aphasia therapy for anomia. Disabil Rehabil 2011;33:229-242.

53 Meinzer M, Beeson PM, Cappa S, Crinion J, Kiran S, Saur D, Parrish T, Crosson B, Thompson CK: Neuroimaging in aphasia treatment research: consensus and practical guidelines for data analysis. Neuroimage 2012, E-pub ahead of print.

-54 Fonseca JM, Farrajota L, Leal G, Castro-Caldas A: Aphasia ten years later. J Clin Exp Neuropsychol 1993; 15:398.

55 Pulvermüller F, Berthier ML: Aphasia therapy on a neuroscience basis. Aphasiology 2008;22:563599.

56 Frattali C, Thompson C, Holland A, Wohl C, Ferketic M: American Speech-Language-Hearing Association Functional Assessment of Communication Skills for Adults. Rockville, MD, ASHA, 1995. 